\title{
A Boiler Room in a 600-Bed Hospital Complex: Study, Analysis, and Implementation of Energy Efficiency Improvements
}

\section{Juan-Carlos Fraile ${ }^{1}$, Julio San-José ${ }^{2, *}$ and Ana González-Alonso ${ }^{2}$}

1 Institute of Advanced Production Technologies, School of Industrial Engineering, University of Valladolid, C/Paseo del Cauce 59,47011 Valladolid, Spain; E-Mail: jcfraile@eii.uva.es

2 Department of Energy Engineering and Fluid Mechanics, School of Industrial Engineering, University of Valladolid, C/Paseo del Cauce 59, 47011 Valladolid, Spain;

E-Mail: ana87_gonzalez@hotmail.com

* Author to whom correspondence should be addressed; E-Mail: julsan@eii.uva.es; Tel.: +34-983-423-685, Fax: +34-983-186-462.

Received: 8 April 2014; in revised form: 8 May 2014 / Accepted: 13 May 2014 /

Published: 19 May 2014

\begin{abstract}
The aim of energy efficiency is to use less energy to provide the same service. In hospitals, energy efficiency offers a powerful and cost-effective tool to reduce greenhouse gas emissions, fuel consumption, and also running costs. Over a six-month period, the six gas-fired boilers that provide both a hospital's heat and hot water were monitored. Analysis of the data obtained led to several actions being implemented in the hospital boiler room control system to improve the efficiency of the heat production system. Comparative studies were conducted, during similar weather periods, of the performance of the hospital's hot water production system before and after the controls were implemented. Results indicate that the control actions applied proved to be effective. Finally; the paper offers a financial; primary energy saving and $\mathrm{CO}_{2}$ reduction analysis that points to a $3,434.00 €$ /week savings in natural gas consumption; and a cut in $\mathrm{CO}_{2}$ emissions of 20.3 tons/week; as compared to the reference facility.
\end{abstract}

Keywords: energy efficiency; hospital; boiler room control

\section{Introduction}

Hospitals and health care buildings traditionally have high energy demands for both mechanical power and heat. Mechanical power in the form of electrical energy is used for lighting as well as 
technological and medical equipment. Heat is required for space heating needs, sanitary hot water, and steam production.

Increasing demand for comfort in rooms coupled with high internal loads has led to a significant increase in cooling requirements over the last decade. As a result, hospital heating and cooling systems which rely on conventional Heating, Ventilation and Air-Conditioning (HVAC) units are both energy intensive and expensive. To reduce energy use and greenhouse gas emissions by these facilities, the health care sector needs energy efficient solutions operating at the lowest cost [1].

This energy is often used inefficiently and may be due to the control/operation of the building [2]. Properly functioning control systems (input and output devices, controllers...), are a significant contributor to energy efficiency. Problems associated with building controls and operation are a primary cause of inefficient energy usage. Hardware failures, software errors, and human factors related to the difficulty of use and understanding of control products all conspire to prevent buildings from achieving the desired energy efficiency.

In a 60 building study, researchers at Lawrence Berkeley National Laboratories found that $50 \%$ of the buildings evidenced control problems; $40 \%$ evidenced HVAC equipment problems; $25 \%$ employed Energy Management Control Systems (EMS) that did not function properly; and $15 \%$ had missing equipment [2]. This demonstrates that solving control related problems contributes significantly towards primary energy saving.

According to the USA Department of Energy [3], over 50\% of the energy used in buildings is consumed by HVAC units and lighting systems. However, research has shown that up to $40 \%$ of this energy can be saved by closely monitoring the state of the building and applying suitable control strategies [4]. The complexity of the acquired sensory data and the overwhelming amount of information presented makes such control systems difficult to adjust or even understand by responsible building managers [5].

There are around 800 hospitals in Spain, and the health sector is eminently public in nature, to the extent that 108,000 of the country's 160,000 beds are in public hospitals. Consumption in the hospital sector in Spain reached 0.6 Mtep, accounting for $6 \%$ of the total service sector consumption, and representing expenditure amounting to some 600 million euros. Energy consumption studies performed in Spanish hospitals are shown in Table 1, and reflect mean energy consumption per bed in one year for the various areas of consumption [6].

Table 1. Mean energy consumption per bed and year in Spanish hospitals.

\begin{tabular}{ccccc}
\hline Hospitals & $\begin{array}{c}\text { Electricity } \\
\mathbf{( k W h} / \mathbf{b e d} \cdot \mathbf{y e a r})\end{array}$ & $\begin{array}{c}\text { Natural gas } \\
\mathbf{( k W h} \cdot \mathbf{H H V} / \mathbf{b e d} \cdot \mathbf{y e a r})\end{array}$ & $\begin{array}{c}\text { Diesel } \\
\mathbf{( k W h} \cdot \mathbf{H H V} / \mathbf{b e d} \cdot \mathbf{y e a r})\end{array}$ & $\begin{array}{c}\text { Propane } \\
\mathbf{( k W h} \cdot \mathbf{H H V} / \mathbf{b e d} \cdot \mathbf{y e a r})\end{array}$ \\
\hline$>300 \mathrm{beds}$ & 10,043 & 14,722 & 6,733 & 102 \\
$<300$ beds & 8,885 & 7,987 & 12,695 & 229 \\
\hline
\end{tabular}

Hospitals provide a wide range of services, each of which has its own specific energy requirements. These needs, however, are met through centralized management systems. The energy consumed in a hospital is directly proportional to demand and inversely proportional to system efficiency. Demand depends primarily on: the skin of the building, the use to which the building is put, ventilation requirements, prevailing weather conditions in the area, and so on [7]. 
System efficiency requires properly designed system components, suitable interrelation amongst components and control strategy for each element, as well as for the system as a whole. This is reflected when considering the various factors involved in a centralized heating system (see Figure 1): (a) the functions of the equipment (heat production, distribution, and thermal emittance); (b) thermal reservoirs (boilers, distribution, thermal emittance, premises, and outdoor environment); and (c) communication and regulation (generator, distribution, thermal emittance, general control).

Figure 1. Block diagram of a standard heat generating system.

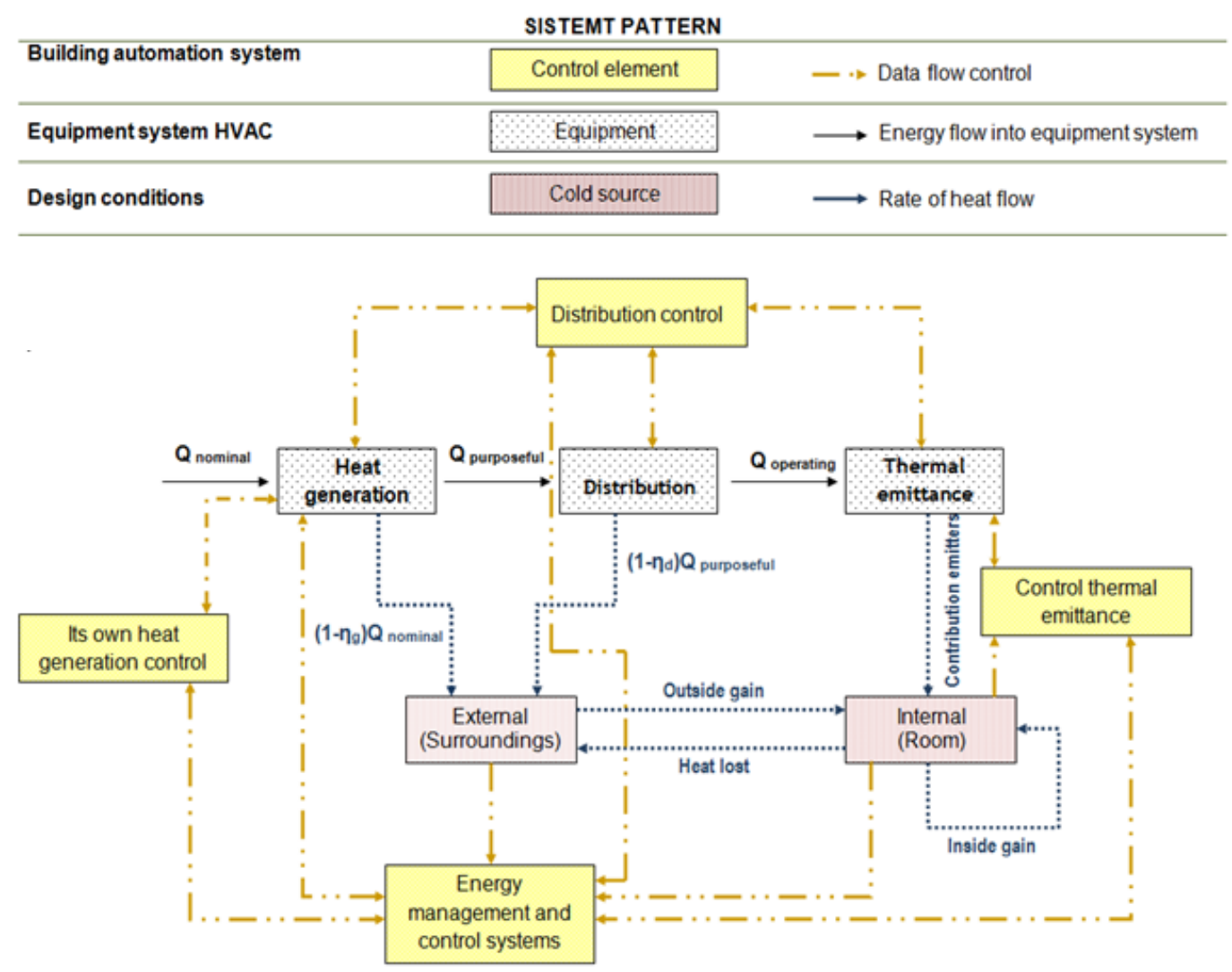

The regulation and control of all these factors that intervene in a central heating system require Building Automation and Control Systems (BACS). BACS include information concerning all signals from the buildings in order to get "intelligent buildings". The systems integrated into the BACS pursue diverse and very different purposes, so integration issues are of particular importance. Compared with the field of industrial automation, building automation has specific and different characteristics [8].

This has created a large quantity of research to improve HVAC energy by monitoring and regulation BACS. Vakiloroaya [9] presented the improved energy efficiency of an air cooling plant, introducing the model-based gradient projection optimization method. Chung [10] developed a communication software that collects data on energy consumption and estimates consumption. Bujak [11] improves the energy efficiency of a steam thermal power plant using mathematical modeling; Klein [12] reduced energy consumption by increasing the number of sensors and computational support of the Energy Management Control Systems (EMCS). Yoshida [13] performed an analysis of energy supply in hospitals, based on a sensitivity analysis. Ma and Wang [14] improved the control strategy of a centralized cooling plant's efficiency. Beghi [15] has designed an adaptive control for a toilet 
air-cooled chiller, which has managed to increase energy efficiency by $3 \%-7.3 \%$; while Liao [16] studied a load prediction by occupation in commercial buildings. West [17] presented an optimised supervisory model predictive control (MPC) system for heating, ventilation and air conditioning (HVAC) in commercial buildings.

As is clear from these reviews, improving energy efficiency by developing new software packages for BACS is a very broad research field, due to the large number of variables and parameters that have to be considered. The EMCS currently ensures the safety and operation of energy facilities, but the optimal energy efficiency of the installation still requires work and experimentation.

This article describes the improvements in energy efficiency in a centralized heating facility in a 600 -bed hospital complex covering a built-up area of $170,000 \mathrm{~m}^{2}$. The implemented improvements reduce the periods in which the hospital's heat production system is on STANDBY, and therefore, also reduces the TRANSITION times. Improvements were made over the summer for three reasons: (i) tests and adjustments have less impact on the hospital's comfort level; (ii) results can be fully extrapolated to winter, as well as periods between the extreme seasons; and (iii) the cost of performing tests is lower, since these are carried out when the boilers are working at less power.

\section{Materials and Methods}

\subsection{Methodology for Reducing Hospital Costs through Energy Efficiency}

The energy efficiency of an HVAC installation is improved by a process of energy management. Energy management is a cyclical process (see Figure 2), with the following sections: (i) Initial state; (ii) Analysis of information; (iii) Proposed actions and implementation; (iv) Analysis of results. Once these four phases are completed, the process of collecting data begins again to assess the improvement in energy efficiency and continue the process of continuous improvement [18].

Figure 2. Methodology for increasing the energy efficiency of an Heating, Ventilation and Air-Conditioning (HVAC) installation.

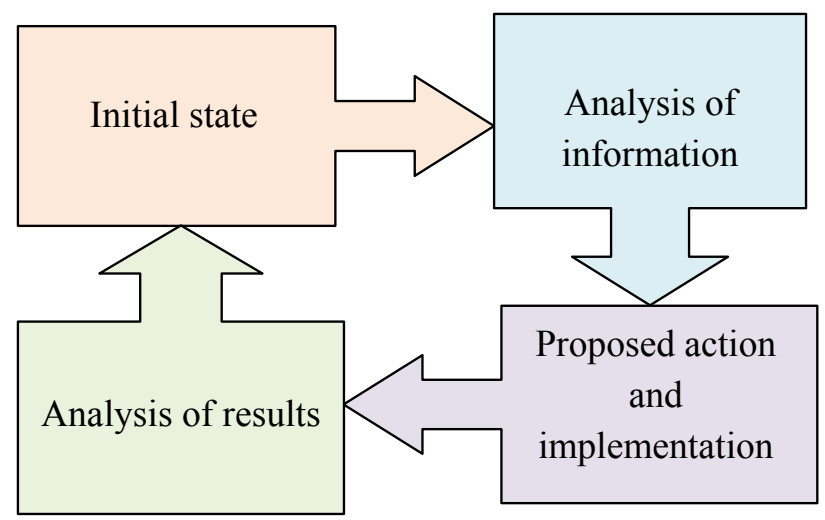

This method is applicable to HVAC facilities as a whole (full system) or to sub-systems. In both cases, the variables which the particular environment imposes on the system or sub-system need to be known. Given the complexity of a 600-bed hospital's HVAC facilities, the best option is to undertake the analysis in subsystems. In this case, work began with one of the subsystems which has the greatest impact on the hospital's energy consumption, the heating system. Since the case in hand was a fully 
operational hospital, a study was carried out over the summer, since any problems in the HVAC system during the winter would prove totally unacceptable. BACS is a system which allows data to be gathered and analyzed systematically, and which in many instances enables the proposed actions to be implemented, in such a way that, throughout the study, close attention must be paid to the system's configuration and functioning [19].

The boiler room's energy efficiency may be determined directly as a ratio between useful power and power consumed. However, if a more detailed analysis is to be performed, an indirect evaluation should be carried out in terms of the system's losses, linked to the useful energy as indicated in Equation (1):

$$
\eta=\frac{\text { Useful power }}{\text { Power consumption }}=\frac{\text { Power comsumption }-\sum \text { Loss }}{\text { Power consumption }}
$$

The heat station efficiency is determined in specific periods of time, which might be annual, in winter, summer, and so on, using power consumption and loss over a particular period of study.

Over a given period of its functioning, the system may be in one of three modes:

(a) ON: when generators supply energy to the system. In these cases, it is assumed that the building requires energy. Losses associated to this mode are:

- Heating stack loss $\left(P_{\mathrm{h}}\right)$.

- Losses caused by the facility's convection and radiation $\left(P_{\mathrm{cd}}\right)$.

- Losses caused by maladjustments in the control system $\left(P_{\mathrm{r}}\right)$.

(b) STANDBY: when generators supply no energy to the system. In these cases, it is assumed that the building requires no energy. Losses associated to this mode are:

- Heating stack loss caused by chimney draught $\left(P_{\mathrm{i}}\right)$.

- Losses caused by the facility's convection and radiation $\left(P_{\mathrm{cd}}\right)$.

- Losses caused by maladjustments in the control system $\left(P_{\mathrm{r}}\right)$.

(c) TRANSITION STAGE: when the system generators switch from STANDBY to ON. In these cases, the building changes from requiring no energy to requiring energy. Losses associated to this mode are:

- Losses caused by flue gas vent $\left(P_{\mathrm{pr}}\right)$.

- Losses caused by the facility's convection and radiation $\left(P_{\mathrm{cd}}\right)$.

- Losses caused by maladjustments in the control system $\left(P_{\mathrm{r}}\right)[20,21]$.

When determining a system's efficiency over a given period, the system is checked to see whether it has been: in ON mode $\left(t_{\mathrm{ON}}\right)$, in OFF mode ( $\left.t_{\mathrm{STANDBY}}\right)$, or in transition mode $\left(t_{\mathrm{TRANSITION}}\right)$. The system's total energy loss is calculated as:

$$
\sum \text { Loss }=t_{\mathrm{ON}} \times\left(P_{\mathrm{h}}+P_{\mathrm{cd}}+P_{\mathrm{r}}\right)+t_{\text {STANDBY }} \times\left(P_{\mathrm{i}}+P_{\mathrm{cd}}+P_{\mathrm{r}}\right)+t_{\text {TRANSITION }} \times\left(P_{\mathrm{pr}}+P_{\mathrm{cd}}+P_{\mathrm{r}}\right)
$$

Power consumed will be the power of the boiler $\left(P_{\text {boiler }}\right)$ during the time it was $\mathrm{ON}$ and is calculated as:

$$
\text { Power consumption }=t_{\mathrm{ON}} \times P_{\text {boiler }}
$$

Replacing all these terms in the system's efficiency expression for a specific period gives: 


$$
\eta=\frac{t_{\mathrm{ON}} \times P_{\text {boiler }}-t_{\mathrm{ON}} \times \sum P_{\mathrm{ON}}-t_{\text {STANDBY }} \times \sum P_{\mathrm{STANDBY}}-t_{\text {TRANSITION }} \times \sum P_{\mathrm{TRANSITION}}}{t_{\mathrm{ON}} \times P_{\text {boiler }}}
$$

This expression reflects how losses can be reduced by using more efficient equipment and recovery systems when the system is ON, although losses cannot be totally eliminated. However, it is possible to eliminate losses when the system is in STANDBY or TRANSITION mode by suitably adapting the equipment to demand and by eliminating transition periods. Improvements in the boiler room's energy efficiency will reduce transitional periods, which will mean that the boilers operate continuously as much time as possible.

\subsection{Description of the Hot Water Distribution System in the Hospital}

The boiler and hot water distribution system in the hospital came into operation in 2009. The hospital comprises several large buildings, consisting of four floors, with 600 beds, operating theatres, as well as technical and consultation rooms. It operates every day of the year on a 24-hour-a-day basis. Gas-fired boilers were installed to meet the hospital's heating demands. The boiler room comprises a group of six gas-fired boilers. These boilers are the Eurobloc-super standard model, manufactured by Vulcano-Sadeca [22]. Burners are the Weishaupt RGL (R: modulating regulation; G: gas and L: liquid fuel) model, which combines diesel/natural gas burners. Four boilers (B1, B2, B3, and B4) are equipped with a heat power of $4000 \mathrm{~kW}$ each. Boiler 5 (B5) has a $2300 \mathrm{~kW}$ generator, and boiler 6 (B6) has an $1100 \mathrm{~kW}$ generator. Such a variety of powers allows a wide range of possibilities to adapt to the hospital's energy requirements. Hot water produced by boilers is pumped through pipes by means of two circuits:

- Primary circuit (red in Figure 3): The gas-firedboilers are connected to this circuit which is a closed loop. When hot water leaves the boilers, the supply pump units drive it through the heat exchangers, transmitting heat to the air and to the sanitary water. The water then returns to the boiler by means of return pump units.

- Secondary circuit (blue in Figure 3): The hot water flowing through this circuit is used to supply heating requirements in certain areas of the hospital (patients' rooms, operating theatres, and so on) by means of fan coils, and to heat sanitary water stored in tanks. In both cases, heat transfer is carried out through heat exchangers.

The flow in the primary circuit is variable, while the flow in the secondary circuit is constant. The bypass enables differences in water flow to be compensated for. This bypass also helps to raise the temperature of the water returning to the boilers, making the temperature jump in the boiler the best possible.

Energy management and control systems (EMCS) in buildings are widely used due to their high potential for saving energy and cutting consumed energy expenses. The goal of an EMCS is to combine indoor comfort conditions at the zone/room level of the building with an energy saving strategy, monitoring the performance of the overall system and adapting the control strategy accord-ingly [23,24]. 
Figure 3. Primary and secondary circuits of the hospital's hot water distribution system.

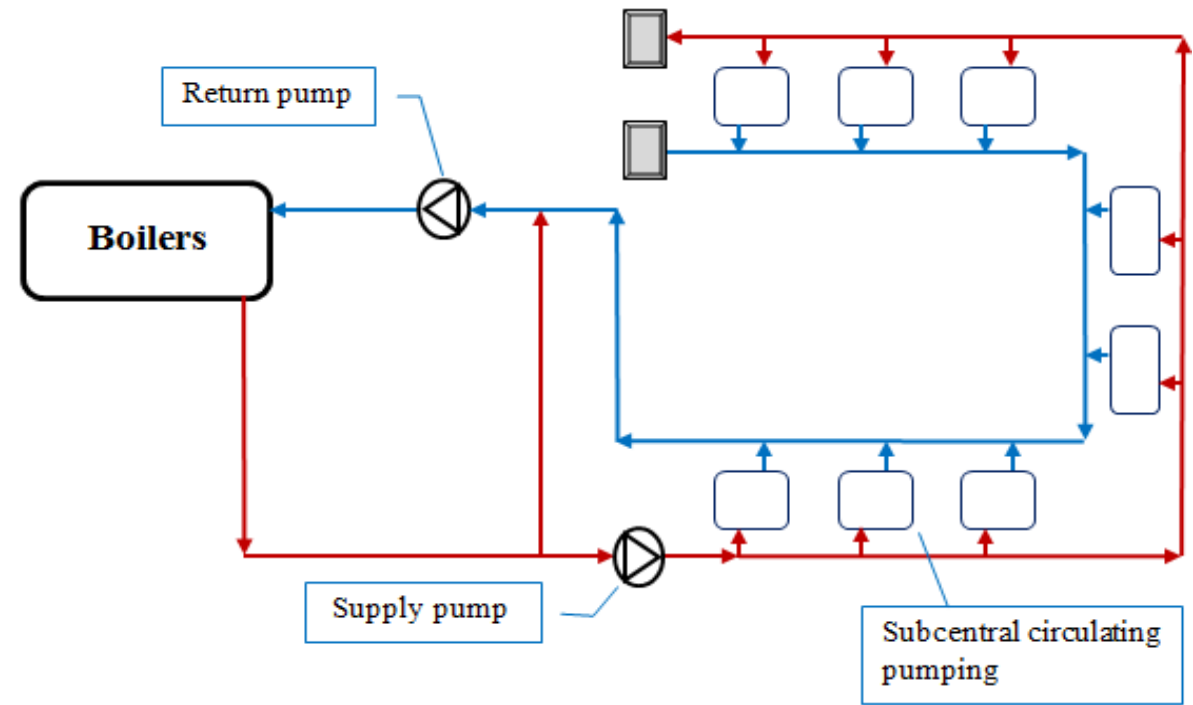

The hospital EMCS integrates sensors, actuators, interfaces, controllers, local area network (LAN) and two PCs for monitoring. All of them are interconnected in a centralized control architecture. The EMCS controls and monitors a wide variety of services, such as radiator systems, fan coil units, air handlers, gas-fired boilers, sanitary hot water, as well as monitoring medical gases.

All the control components for producing heat and domestic hot water in the hospital are manufactured by Trend ${ }^{\circledR}$ (Horsham, UK) [25,26]. A LON (Local Operation Network) connects all the controllers Trend with trade name IQL, and four Local Area Networks (LANs) link up the controllers Trend with trade name IQ2XX. Trend 963 software allows data, control settings, and the development of the new control strategy for boiler controllers to be monitored.

Figure 4 shows the architecture of the EMCS systems with four LANs, interconnected through an internet network by means of cards Trend with trade name INC2. Two PCs in the hospital control room are linked through LAN networks by means of cards Trend with trade name CNC2.

Figure 4. The architecture of the hospital EMCS.

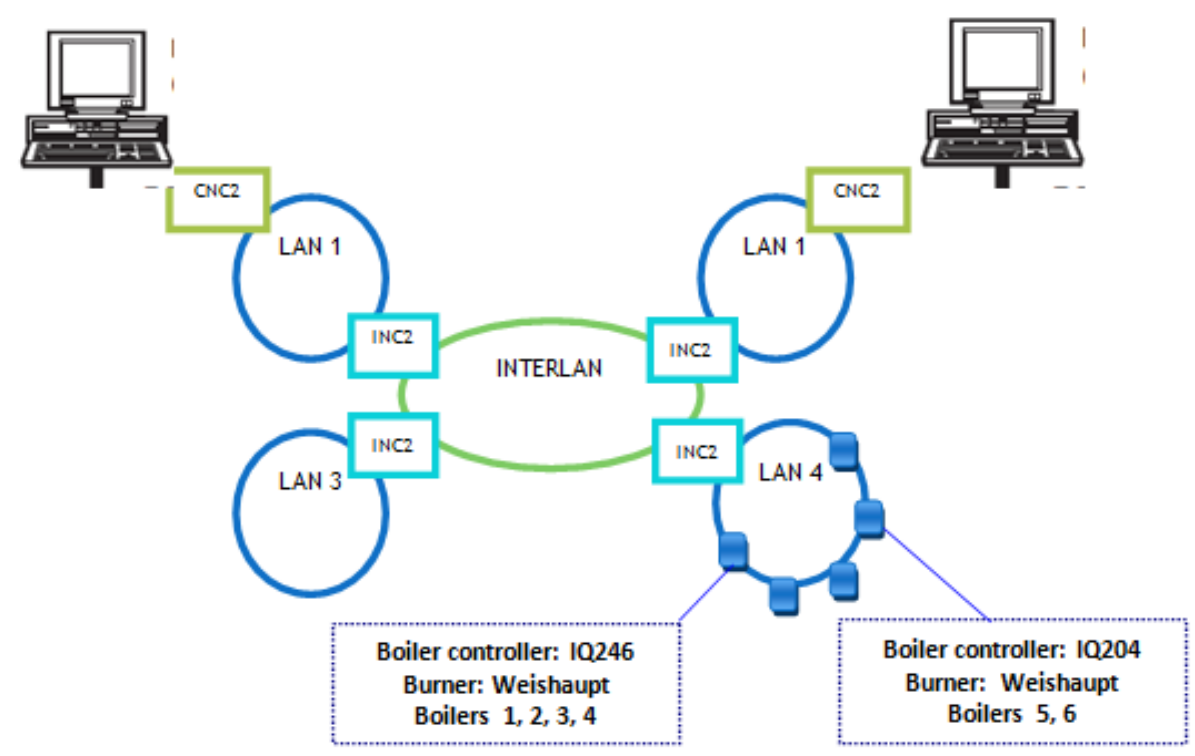


The controllers of the six boilers that make up the hospital's heat generating system are linked to the LAN 4 network. Boilers 1, 2, 3, and 4 use controllers Trend with trade name IQ246, and boilers 5, and 6 use controller IQ204. In addition, the Weishaupt-Bremer modulating burner in each of the boilers allows the PID (Proportional-Integral-Derivative controller) controller parameters to be regulated.

Improvements in the control strategies were implemented and tested in the primary circuit of the hospital's hot water distribution system (see Figure 4), and more specifically in the functioning of boilers 5 and 6 , which are responsible for supplying the hospital's heating requirements.

\section{Application of the Methodology for Energy Efficiency in the Hospital}

\subsection{Hospital Boiler Control System: Initial State}

The initial basic requirements related to boilers 5 and 6 for providing the hospital's heating requirements are:

- The hot water supply temperature is controlled to meet the setpoint, depending on which services are required by the hospital. Setpoint temperatures may be fixed (the same value over time) or variable (based on building loads or outdoor-air temperature).

- The most efficient groups of boilers at each moment should be used. That is, the groups of boilers which best fit the specific needs at any given moment.

- The number of boiler stops and starts should be minimized, so as to reduce both consumption and mechanical wear.

Regulating the heat production system for heating and sanitary hot water in the hospital involves three parameters which affect system performance:

- Boiler hot water supply temperature.

- Burner power.

- Burner controller PID parameters.

When we started the analysis of the control system that regulates boilers 5 and 6 for providing the hospital with heat and hot water, the setpoint of the hot water supply temperature was $77^{\circ} \mathrm{C}$. The burners of these boilers incorporate a thermostat which, for safety reasons, switches off when the water temperature rises $6{ }^{\circ} \mathrm{C}$ above the setpoint $\left(83^{\circ} \mathrm{C}\right)$. The burners of boilers 5 and 6 were initially adjusted so that their minimum operating power was $50 \%$. These burners are controlled by PID. The default values (given by the manufacturer) of these burners are:

- Maximumburneroperatingpower: $100 \%$

- Minimum burner operating power: $50 \%$

- Setpoint hot water supply temperature: $77^{\circ} \mathrm{C}$

- Safety stop hot water temperature: $83{ }^{\circ} \mathrm{C}$

- PID burner: $K_{\mathrm{p}}=10$

- PID burner: $T_{\mathrm{i}}=10 \mathrm{~s}$

- PID burner: $T_{\mathrm{d}}=10 \mathrm{~s}$ 
Using these initial regulation parameters, data of the hospital's heat production system were collected over a six-month period. The evolution of the "hot water supply temperature" and "burner power" was saved. Data for these variables were taken each two seconds.

Figures 5 and 6 show some of the data collected. Specifically, Figure 5 shows the evolution of the hot water supply temperature in boiler 5 for one hour (early afternoon: 12 h 50'-13 h 50'). Figure 6 shows the burner operation power of boiler 5 during the same period of time.

Figure 5. Boiler 5: Hot water supply temperature $\left({ }^{\circ} \mathrm{C}\right)$.

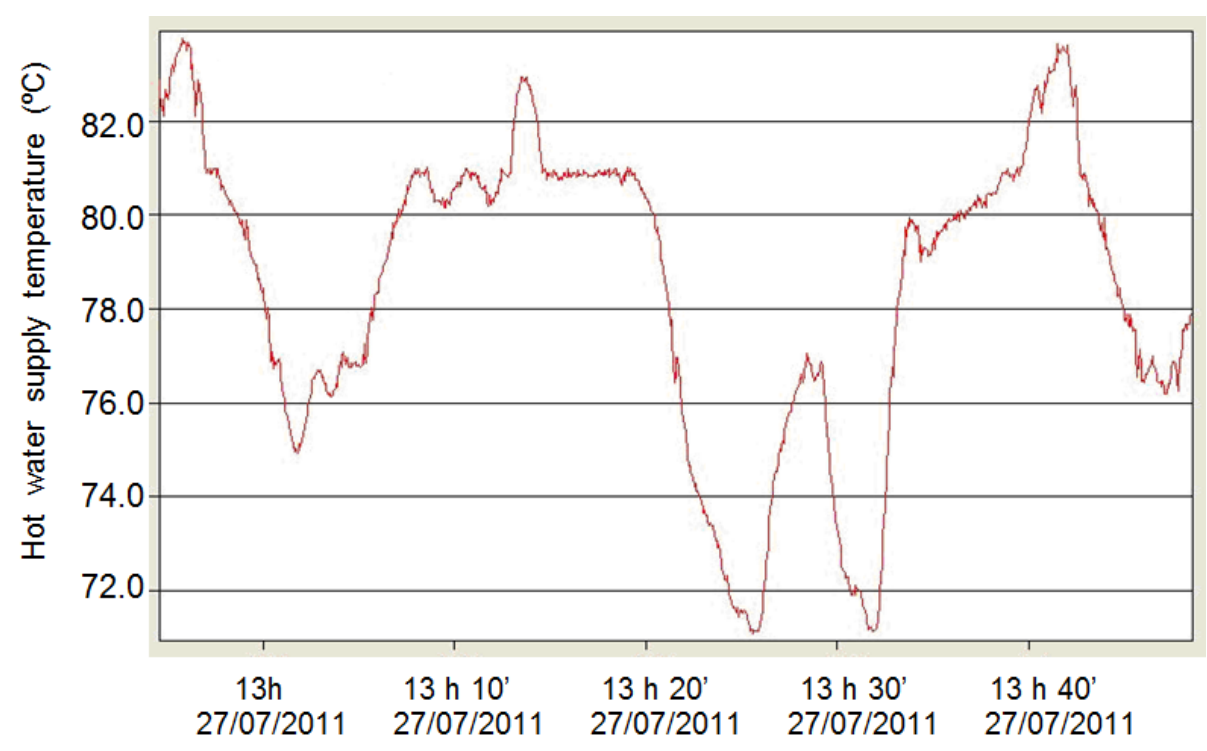

Figure 6. Boiler 5: Burner operating power (\%).

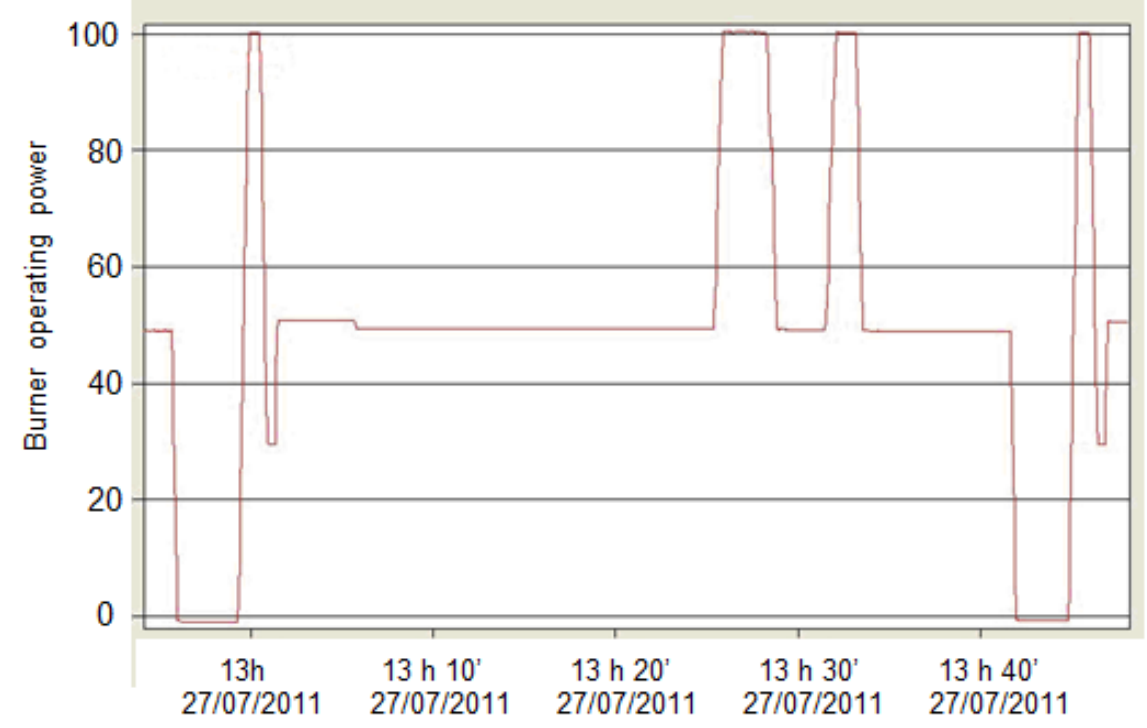

\subsection{Analysis of Information}

Analysis of Figure 5 indicates that the hot water supply temperature takes a maximum value of $84{ }^{\circ} \mathrm{C}$ and a minimum of $71^{\circ} \mathrm{C}$. There is a wide oscillation of $13{ }^{\circ} \mathrm{C}$ over one period (early afternoon: $12 \mathrm{~h} \mathrm{50}-13 \mathrm{~h} \mathrm{50}$ ') when the hospital heating requirements remain constant. Hot water supply temperature should therefore evidence "very few" oscillations. 
Analysis of Figure 6 shows that the burner in boiler 5 switched on and off several times during one hour, for a period when hospital heat demand remained unchanged. A thorough analysis of the data collected over six months allowed us to pinpoint the following problems:

- The hot water supply temperature in boiler 5 displays a major variation (around $13{ }^{\circ} \mathrm{C}$ ). This indicates that the PID of the burner in boiler 5 is not well tuned, is too slow, and lacks predictive ability.

- There are significant drops in temperature corresponding to the burner switching off (over a 45-min interval, boiler 5 switched on and off several times, which is far from desirable. When the hot water supply temperature gets too high, the burner should decrease its power. It cannot because it has a minimum burner operating power set at $50 \%$.

- Continuous stop-starts in the boilers increase the standby and transition times, leading to a reduction in boiler performance. This means that $t_{\text {STANDBY }}$ and $t_{\text {TRANSITION }}$ play a major role in the power plant functioning, leading to increased plant losses. This is due to maladjustments in the power plant. It is unable to adjust the power consumed to the power actually required by the hospital. This irregular functioning of the boilers leads to significant variations in the hot water supply temperature.

With the original (given by the manufacturer) boiler control system, hospital heat demand is highly unstable and changing. The boilers stop-start too often, leading to wide variations in hot water supply temperature. The hospital boiler control system is unable to cope with changes in demand, which leads to strong variations in the hot water temperature of the distribution circuit. Our goal is to solve the problems of continuous boiler stop-starts, and to avoid major variations in hot water supply temperature, by implementing a series of actions in the hospital boiler regulation and control system.

\subsection{Proposed Actions and Implementation}

Having analyzed the data and determined the problems, four actions were proposed and implemented on boiler 5 and 6 control systems.

Action 1: Reducing the Lower Limit of the Burner Operating Power

The first action was to reduce minimum burner power from $50 \%$ to $30 \%$ in boiler 5 , and from $50 \%$ to $40 \%$ in boiler 6 . These boilers are mixed-type burners, and can use natural gas or diesel as fuel. This means that the minimum power cannot drop too low. If the power falls below $30 \%$, there will be excess air which will increase the amount of oxygen at the boiler outlet. The flue gas temperature decreases and there is a danger of condensation.

Action 2: Tuning PID Parameters to Regulate the Burners of Boilers 5 and 6

Gas-fired boilers use burners which transform the energy contained in gas into thermal energy. They are used in hospitals to supply heating and sanitary hot water needs. In order to achieve high levels of energy efficiency in hospitals that use gas-fired boilers, efficient control and regulation systems need to be installed. 
PID controllers have been widely used in boiler control for a long time. Appropriate tuning of PID controller parameters is achieved through a range of techniques [27], and by drawing on the experience of the "facility operator". However, the non-linear nature of the boiler being controlled makes it difficult to find the correct values for the PID controller parameters, so it is not easy for the PID controller to achieve effective on-line control. Other more complex control techniques, such as fuzzy control, neural networks, adaptive control and predictive control, will improve hospital control system efficiency.

In the hospital covered in this paper, the control system for the boilers is based on a conventional PID controller. For financial reasons, it was not possible to change the burner controller of the boilers. We therefore fine-tuned the burner PID controllers, while the hospital was operating $24 \mathrm{~h}$ a day, 365 days a year.

The variable to be controlled is the hot water supply temperature, to ensure that it is around the setpoint supply temperature $\left(77 \pm 3{ }^{\circ} \mathrm{C}\right)$, and also to ensure the boiler control system responds to changes in heat demand, by rapidly dealing with these variations.

The burner PID controller of boilers 5 and 6 was initially regulated with the default parameters set by the manufacturer $\left(K_{\mathrm{p}}=10, T_{\mathrm{i}}=10, T_{\mathrm{d}}=10\right)$. These parameters are not appropriate for the facility, since, as seen in Figures 5 and 6, the control system for generating heat is unstable, slow, and cannot be predicted.

When regulating a real system which is already operating, such as hospital boilers, one of the most commonly used methods for tuning the PID is the so-called "empirical adjustment". This is based on an analysis of the system's response features in a closed loop. In our system, we use empirical adjustment based on the Ziegler-Nichols method [5].

We tried two different approaches:

- The stability margin method: In this case the controller is switched to pure "proportional action". The gain of the $\mathrm{P}$ controller is continuously increased until the closed loop shows permanent oscillations. In the hospital, is not very suitable to drive the plant into permanent oscillations. For this reason, we could not get appropriate values for PID parameters using this approach.

- The step response method. This method is based on measurement of the system response to a step input. We used this second method to tune the parameters of PID. The PID parameters shown in Table 3 were obtained using this second method.

After applying the Ziegler-Nichols based empirical adjustment method to our heat generating system, the parameters calculated and programmed for the burner PID controller of boilers 5 and 6 are:

- PID burner: $K_{\mathrm{p}}=10$

- PID burner: $T_{\mathrm{i}}=10 \mathrm{~s}$

- PID burner: $T_{\mathrm{d}}=10 \mathrm{~s}$

Action 3: Boiler Control Sequence (for boilers 5 and 6)

Including the boiler operation sequence is important to achieve energy efficiency. In order to make heat production adjust to heat demand in the hospital, we implemented a control sequence for boilers 5 and 6, adapted to the hospital's outdoor-air temperature. Table 2 summarizes the boiler control sequence for boilers 5 and 6 . 
Table 2. Boilers 5 and 6: Control sequence.

\begin{tabular}{ccc}
\hline Outdoor-air temperature & Operating priority & Support sequence \\
\hline OT $\leq 32{ }^{\circ} \mathrm{C}$ & Boiler 5 (B5) & $\begin{array}{l}\text { Power (B5) }>75 \% \text { for } 3 \text { min } \rightarrow \text { B6 on } \\
\text { Power (B6) } \leq 40 \% \text { for } 3 \text { min } \rightarrow \text { B6 off }\end{array}$ \\
\hline OT $>32{ }^{\circ} \mathrm{C}$ & Boiler 6 (B6) & $\begin{array}{l}\text { Power (B6) }>75 \% \text { for } 3 \text { min } \rightarrow \text { B5 on } \\
\text { Power (B5) } \leq 40 \% \text { for 3 min } \rightarrow \text { B5 off }\end{array}$ \\
\hline
\end{tabular}

A test with different Outdoor-air Temperature $(\mathrm{OT})$ values $\left(\mathrm{OT}=25,28,30\right.$, and $\left.32{ }^{\circ} \mathrm{C}\right)$ was performed to study what the OT is for which hospital heat demand can be covered with only boiler output 6 (the smallest). Results showed this to be with OT $=32{ }^{\circ} \mathrm{C}$, since with this value the system performed better. Consequently, if OT $\leq 32{ }^{\circ} \mathrm{C}$, boiler 5 works as the main boiler, whereas if $\mathrm{OT}>32{ }^{\circ} \mathrm{C}$, boiler 6 will be the main boiler.With this OT value, we programmed a support sequence for boilers 5 and 6 (see Table 2), given by:

- If the priority boiler is working at $75 \%$ power for more than three minutes, the other boiler automatically switches on to support it.

- If boilers 5 and 6 are operating, the support boiler will switch off automatically once it has been running at $<40 \%$ power for three minutes.

A three-minute waiting period was chosen to prevent the support boiler starting/stopping unless it was really required to do so. If hospital heat demand increases, and the priority boiler is able to cope, it will increase its power over a short period of time, and the boiler will decrease its power once the heat demand has been covered. In this case, the support boiler does not switch on. However, if the priority boiler is unable to cope with the increased heat demand, and has been running at $100 \%$ power for over three minutes, the support boiler switches on, and the two boilers will be working to cover hospital heat demand.

\section{Action 4: Variable Setpoint for Hot Water Supply Temperature}

The hot water supply temperature should be based on hospital heat demand and outdoor-air temperature. When outdoor-air temperature decreases:

- The hospital areas to be heated need higher air supply temperatures to reach comfort temperature, and

- Hot water is cooler and requires more heat input for heating.

When outdoor air temperature increases, the opposite occurs.

We have developed a new boiler control strategy based on the variable setpoint for the hot water supply temperature, depending on outdoor air temperature. This new control strategy seeks to achieve a better adaptation between hospital heat production and heat demand, maximum energy efficiency for the facility, and lower costs (by consuming less gas and electricity).

The user can choose between the fixed setpoint (manual mode) and the variable setpoint (auto mode). Figure 7 shows the screen for selecting the setpoint mode. In "auto" mode, the user chooses the Outdoor-air Temperature (OT, minimum and maximum values), and the boiler hot water Supply Temperature (ST, minimum and maximum values). The control system makes the linear interpolation 
between these points, obtaining a linear variation of the hot water supply temperature, whose specific value at each moment will depend on the outdoor air temperature measured outside the hospital.

This new variable setpoint control strategy was programmed for the six boilers in the hospital, although, for the time being, it has only been tested and analyzed with boilers 5 and 6 .

Figure 7. Boiler 5: Variable set point strategy for hot water supply temperature.

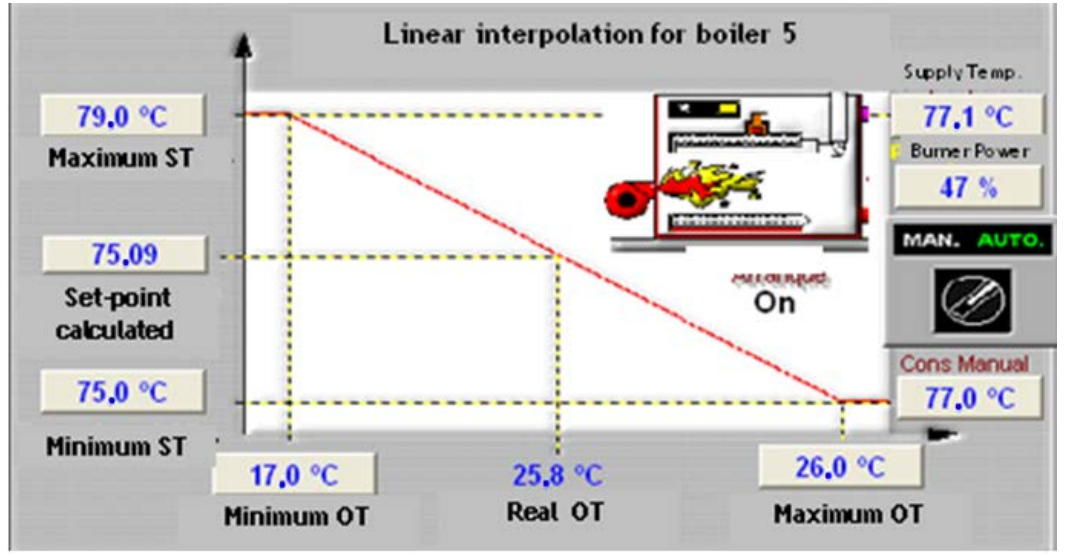

\section{Analysis of Results}

The results of monitoring the hot water supply were analyzed to determine the technical, financial, and ecological performance of the actions implemented on boilers 5 and 6 of the hospital.

\subsection{Results Analysis with Actions 1 and 2 Implemented}

Actions 1 and 2 were performed in the hospital on 2 August. Figure 8 shows the temperature monitoring of the hot water supply for boiler 5 during one hour (13 h-14 h, 13 August 2011). The setpoint is $77^{\circ} \mathrm{C}$. The hot water supply temperature ranges between 73 and $79{ }^{\circ} \mathrm{C}$, an oscillation of $6{ }^{\circ} \mathrm{C}$. This is a good result compared to the $13{ }^{\circ} \mathrm{C}$ oscillation shown in Figure 5 .

Figure 8. Boiler 5: Hot water supply temperature evolution $\left({ }^{\circ} \mathrm{C}\right)$ forone hour, implementing actions 1 and 2.

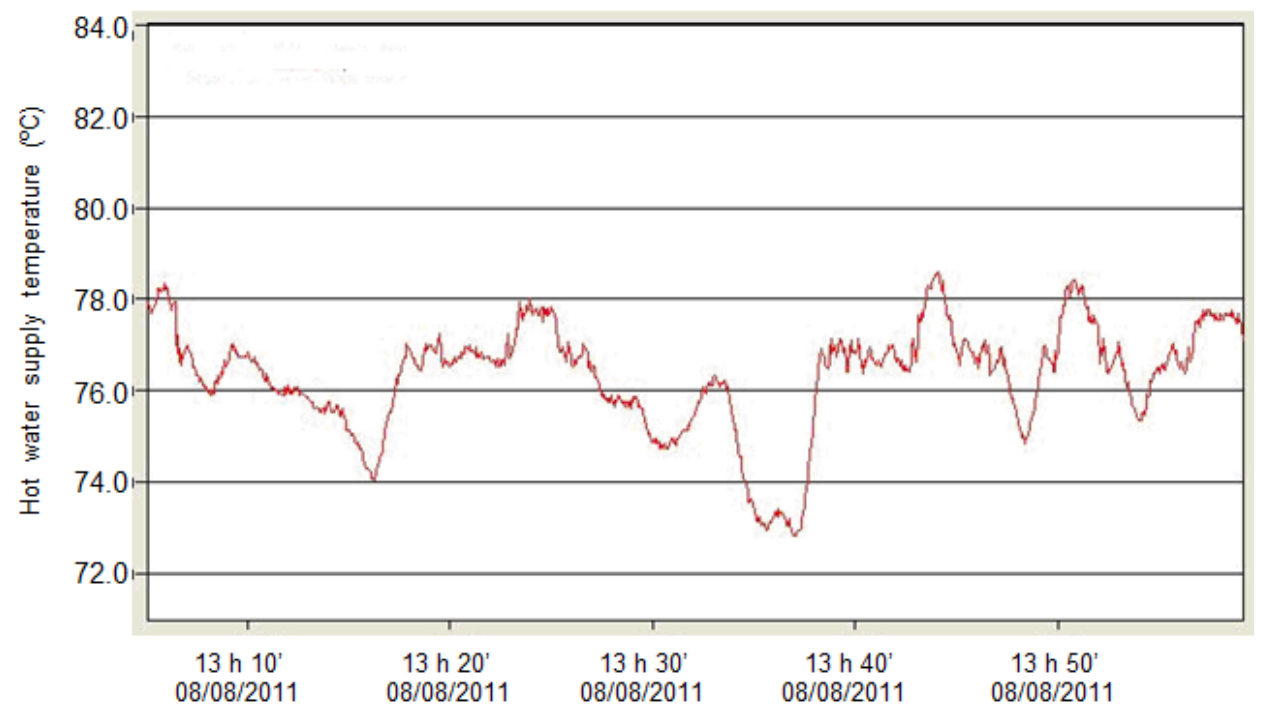


Figure 9 shows the burner operating power for boiler 5 during one hour (13 h-14 h, 13 August 2011). The burner does not stop. It works by adapting its power to the hospital heat demand. This result is better than that depicted in Figure 6, where the burner of boiler 5 switched on and off several times during one hour, causing boiler energy loss and thermal fatigue. Therefore, in boiler 5, demand and consumption are adjusted by regulation, and not by the boiler stopping and starting.

Figure 9. Boiler 5: Burner operating power (\%), implementing actions 1 and 2.

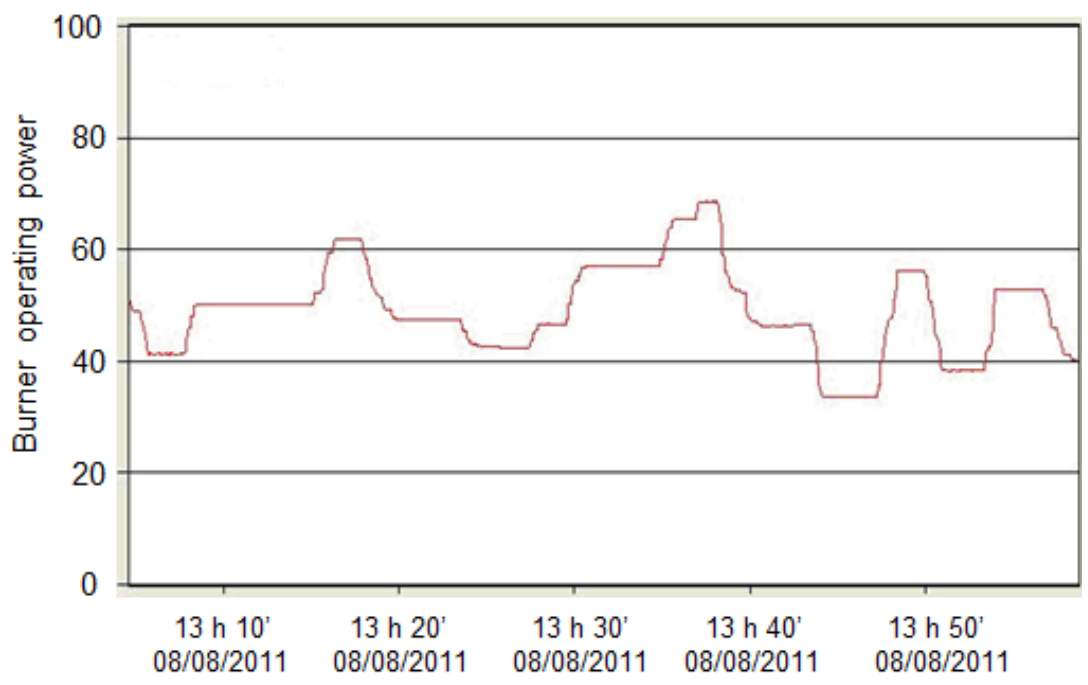

Figure 10 shows the temperature monitoring of the hot water supply for boiler 5 between 30 July 2011 and 8 August 2011. The set point is $77^{\circ} \mathrm{C}$. It should be pointed out that between $9 \mathrm{~h}$ and $11 \mathrm{~h}$ on the morning of 4 August 2011; combustion tests were carried out on boilers 5 and 6 as part of preventive maintenance.

Figure 10. Boiler 5: Hot water supply temperature evolution $\left({ }^{\circ} \mathrm{C}\right)$ implementing actions 1 and 2.

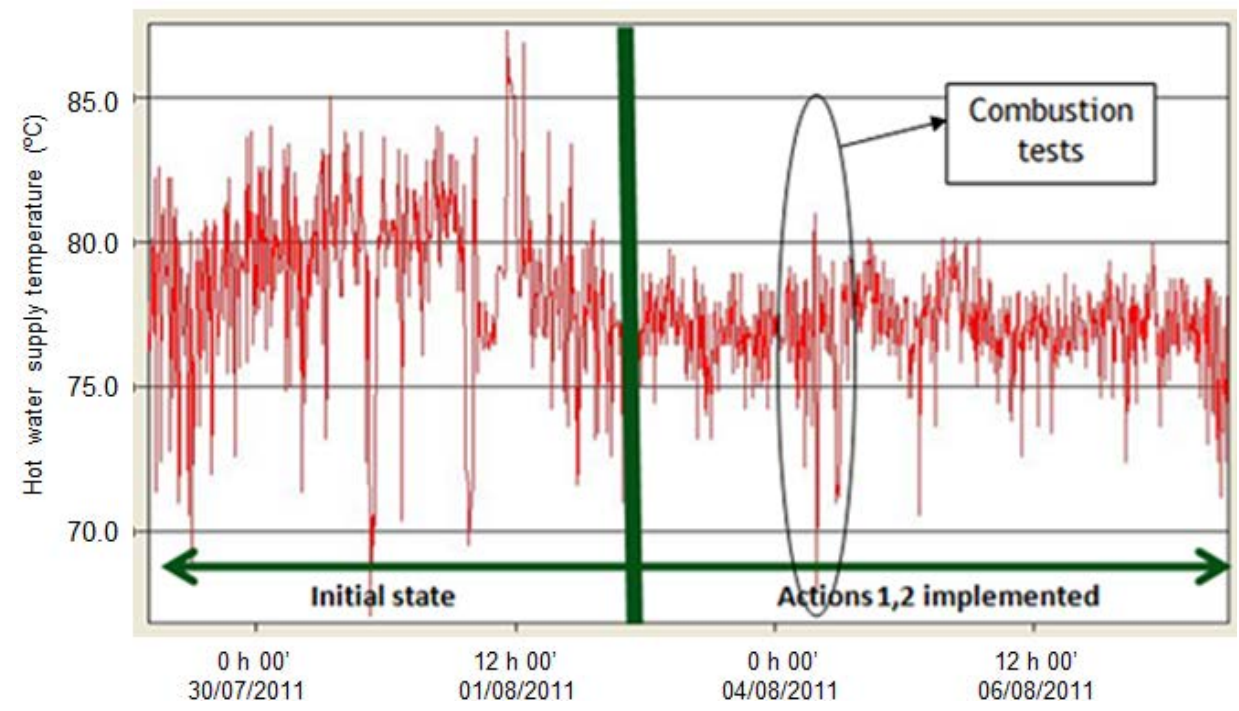

Before 2 August 2011:

- The mean hot water supply temperature in boiler 5 is around $80{ }^{\circ} \mathrm{C}$. Oscillation ranges between 70 and $84^{\circ} \mathrm{C} \rightarrow \pm 7^{\circ} \mathrm{C}$. 
After 2 August 2011:

- The mean hot water supply temperature for the boiler is around $77^{\circ} \mathrm{C}$ (setpoint temperature). The temperature varies between 74 and $80{ }^{\circ} \mathrm{C} \rightarrow \pm 3{ }^{\circ} \mathrm{C}$.

- Temperature peaks have been smoothed and are shorter. By implementing actions 1 and 2, boiler 5 is able to respond rapidly to changes and quickly stabilizes when dealing with changes in demand. Its behavior is much better than that shown in Figure 5.

\subsection{Results Analysis with Actions 1, 2, and 3 Implemented}

Although oscillations in the hot water supply temperature in boiler 5 have been cut substantially and the boiler's control system is running stably, implementing action 3 (boiler control sequence) improves the heat generating system's performance even more, as can be seen in Figure 11. In Figure 11:

- Green line: Boiler 5 supply temperature;

- Red line: Supply temperature into the circuit;

- Blue line: Boiler $6(1=\mathrm{ON}$ and $0=\mathrm{OFF})$;

- Priority boiler: Boiler 5, support boiler: Boiler 6 .

Figure 11 shows the temperature monitoring of the hot water supply for boiler 5 (implementing actions 1, 2, and 3), from $18 \mathrm{~h}$ (15 August 2011) to $10 \mathrm{~h} \mathrm{(16} \mathrm{August} \mathrm{2011).} \mathrm{The} \mathrm{setpoint} \mathrm{is} 77^{\circ} \mathrm{C}$. This interval includes the early hours of the morning ( $05 \mathrm{~h}-09 \mathrm{~h}$ ), when demand is higher because hospital machinery and equipment, which is off during the night, starts up.

Figure 11 shows how, when the hot water supply temperature in boiler 5 decreases (around: $00 \mathrm{~h}$, $06 \mathrm{~h} \mathrm{30}, 07 \mathrm{~h} \mathrm{30}$ '), boiler 6 automatically fires up to support boiler 5 . This prevents a decrease in hot water temperature, keeping the hot water temperature almost constant (around setpoint). The temperature oscillation range has been cut, and now only varies between 75 and $80{ }^{\circ} \mathrm{C}$.

Figure 11. Boiler 5: Hot water supply temperature evolution $\left({ }^{\circ} \mathrm{C}\right)$ implementing actions 1,2 , and 3.

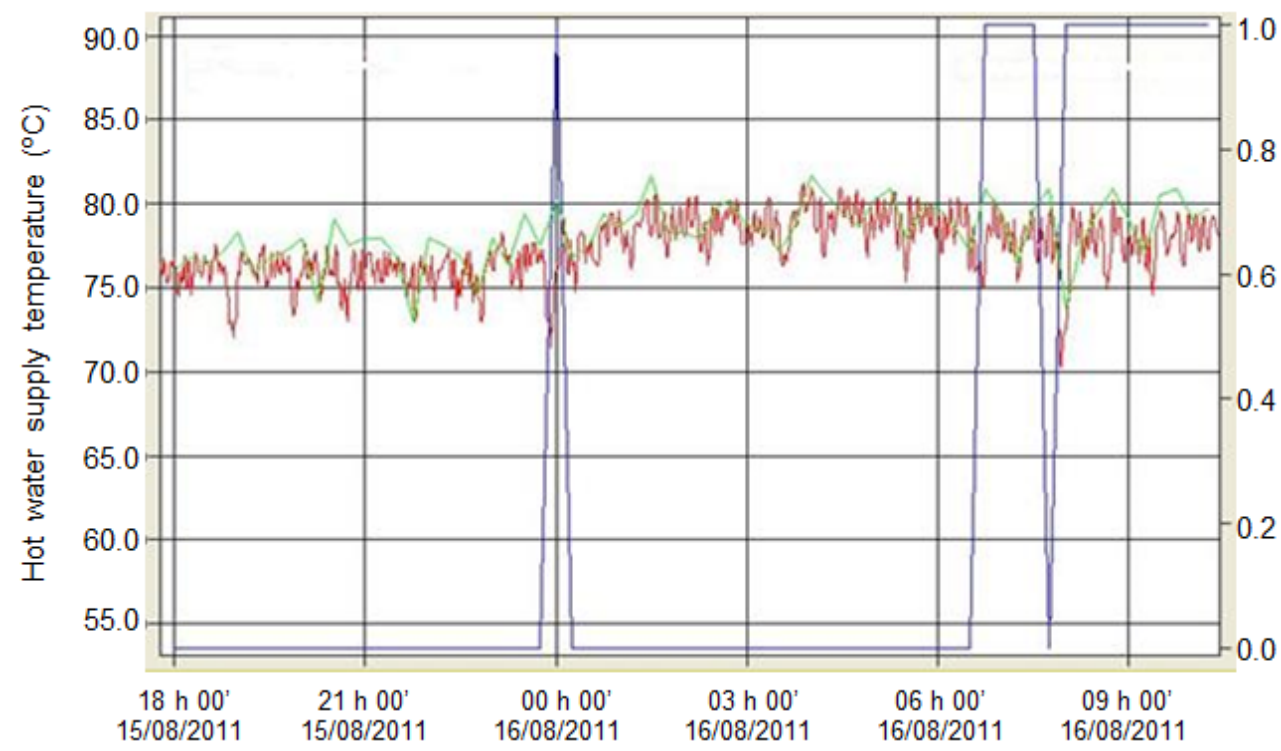




\subsection{Results Analysis with Actions 1, 2, 3, and 4 Implemented}

Finally, Figures 12 and 13 show the results achieved after implementing all the actions described above on boilers 5 and 6 .

Figure 12 shows the temperature monitoring of the hot water supply for boiler 5 from 19 August 2011 to 30 August 2011. Temperature setpoint is constant $\left(77^{\circ} \mathrm{C}\right)$ until 23 August 2011 . The setpoint then varies following the strategy shown in Figure 7. This setpoint variable is characterized by the following values: Minimum OT $=17{ }^{\circ} \mathrm{C}$, maximum OT $=26{ }^{\circ} \mathrm{C}$, minimum $\mathrm{ST}=75^{\circ} \mathrm{C}$, maximum $\mathrm{ST}=79{ }^{\circ} \mathrm{C}$. This figure shows hot water temperature oscillations to suit the variable setpoint programmed.

Figure 12. Boiler 5: Hot water supply temperature evolution $\left({ }^{\circ} \mathrm{C}\right)$ implementing actions 1 , 2,3 , and 4 .

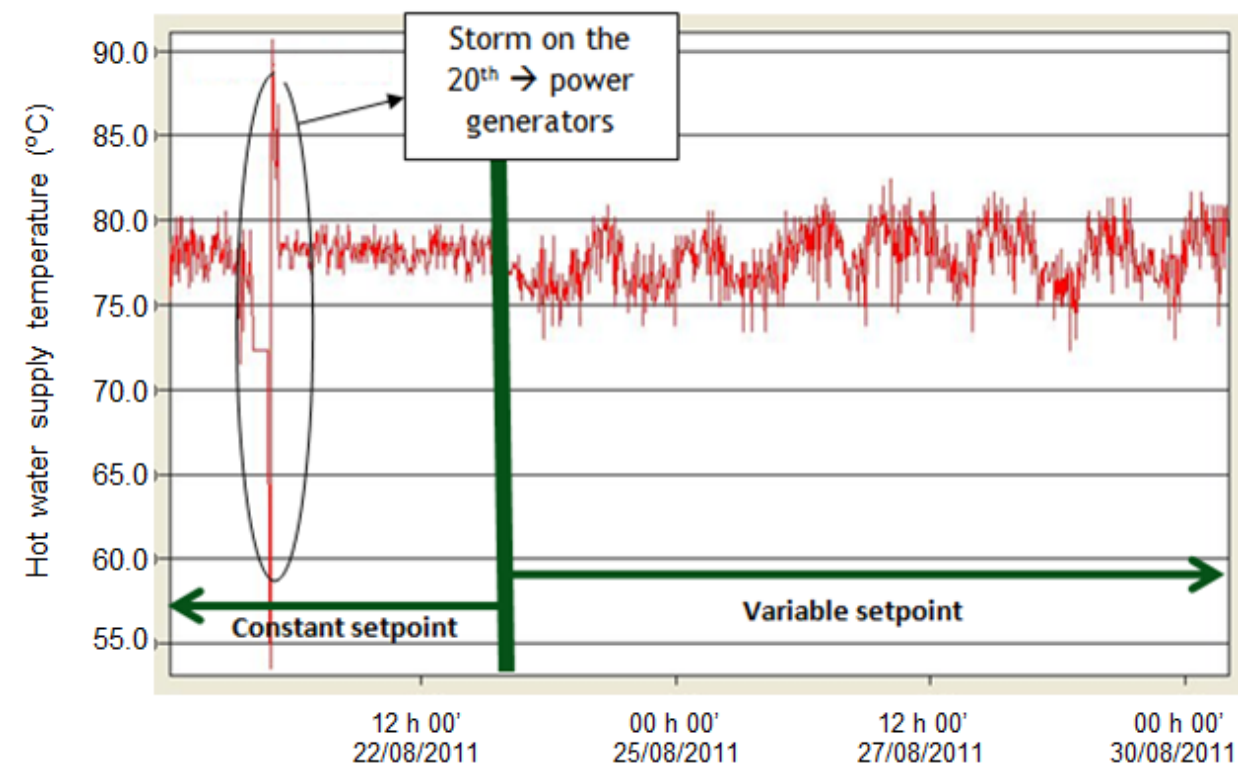

Figure 13. Boiler 5: Hot water supply temperature evolution $\left({ }^{\circ} \mathrm{C}\right)$ and outdoor-air temperature.

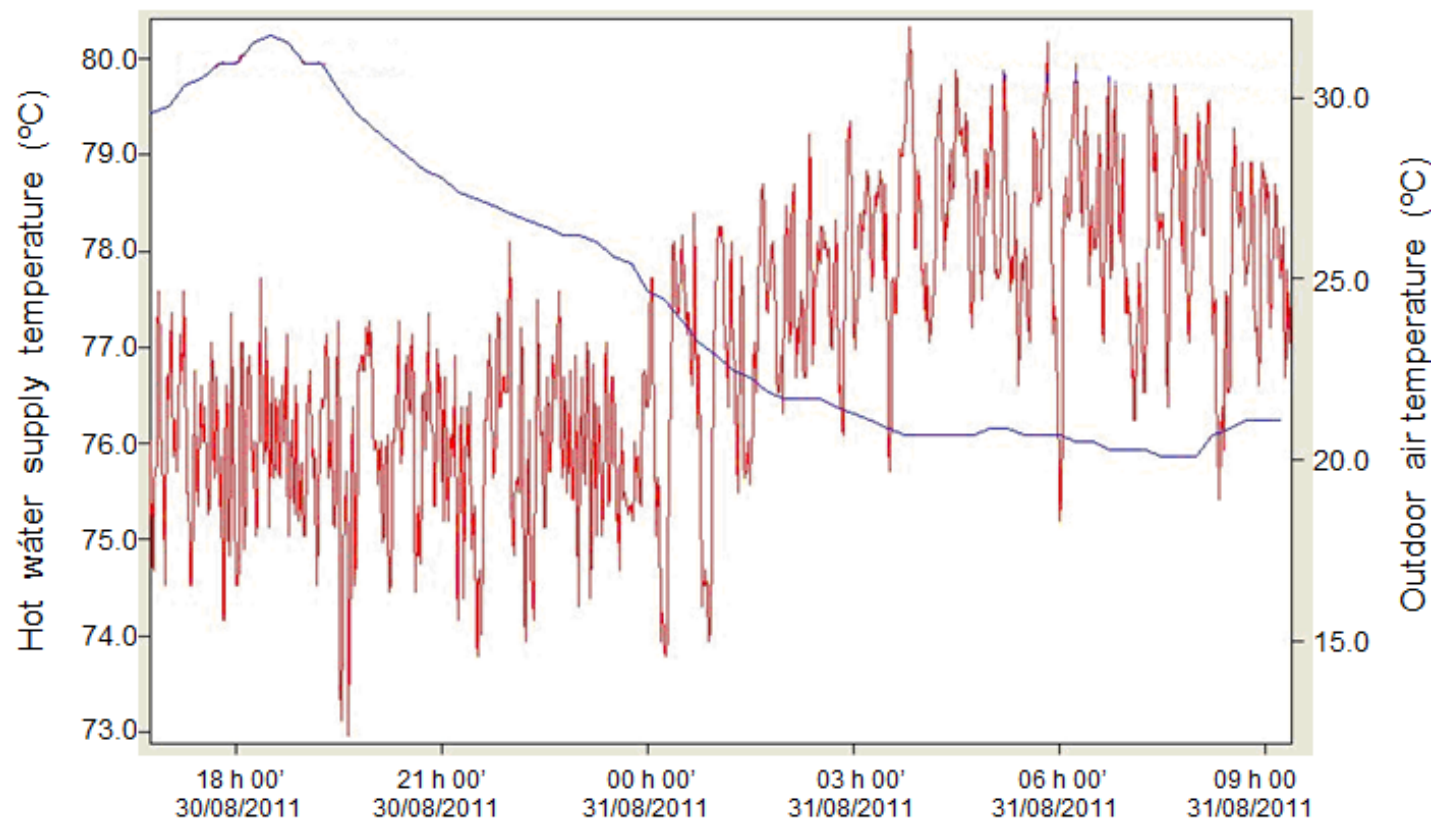


Figure 13 shows temperature monitoring of the hot water supply for boiler 5 (red line) as compared to the outdoor air temperature monitoring (blue line) from $17 \mathrm{~h}$ (30 August 2011) to $09 \mathrm{~h}$ (31 August 2011). This figure shows that the supply temperature is lower during the warmest part of the day (18 $\mathrm{h}-23 \mathrm{~h}$ ). During the night and early hours of the morning $(23 \mathrm{~h}-8 \mathrm{~h})$, when the outdoor air temperature decreases and demand is greatest (due to firing up machines and equipment which lies idle overnight, and hospital patients using bathrooms), the supply temperature is higher.

Therefore, after this analysis, we conclude that the four actions implemented on boilers 5 and 6 allow the boiler control system to respond appropriately to changes in both outside temperature and hospital heating requirements.

\subsection{Primary Energy Savings, $\mathrm{CO}_{2}$ Reduction and Financial Analysis}

The hospital is a major energy consumer. The company supplying natural gas offers access to an online application through which all kinds of information can be obtained: consumption, service conditions, and troubleshooting. This application allows us to choose between daily or hourly consumption depending on how much detail we want.

To determine primary energy saving, a comparison was made between the natural gas consumption in the week of 18 to 24 July 2011 (hospital boiler control system running in initial state, with no action of control implemented), and the week from 12 to 18 September 2011 (hospital boiler control system running in initial state, with control actions 1, 2, 3, and 4 implemented). As it is summer, only boilers 5 and 6 were considered in the study. The other four boilers are not required during the summer. We chose these two weeks because, as shown in Table 3, outside temperatures (maximum, minimum, and average) are very similar, suggesting very similar heating demands in the hospital. Figure 14 shows temperature variations during days 18-24 July 2011, and 12-18 September 2011.

Table 3. Temperature values during the weeks analyzed.

\begin{tabular}{cccc}
\hline Weekly temperatures & Maximum $^{\circ} \mathbf{C}$ & Minimum $^{\circ} \mathbf{C}$ & Average $^{\circ} \mathbf{C}$ \\
\hline 18-24 July 2011 & 27.7 & 14.2 & 20.9 \\
12-18 September 2011 & 27.5 & 14.9 & 21.2 \\
\hline
\end{tabular}

Figure 14. Temperature variation during 18-24 July 2011 and 12-18 September 2011.

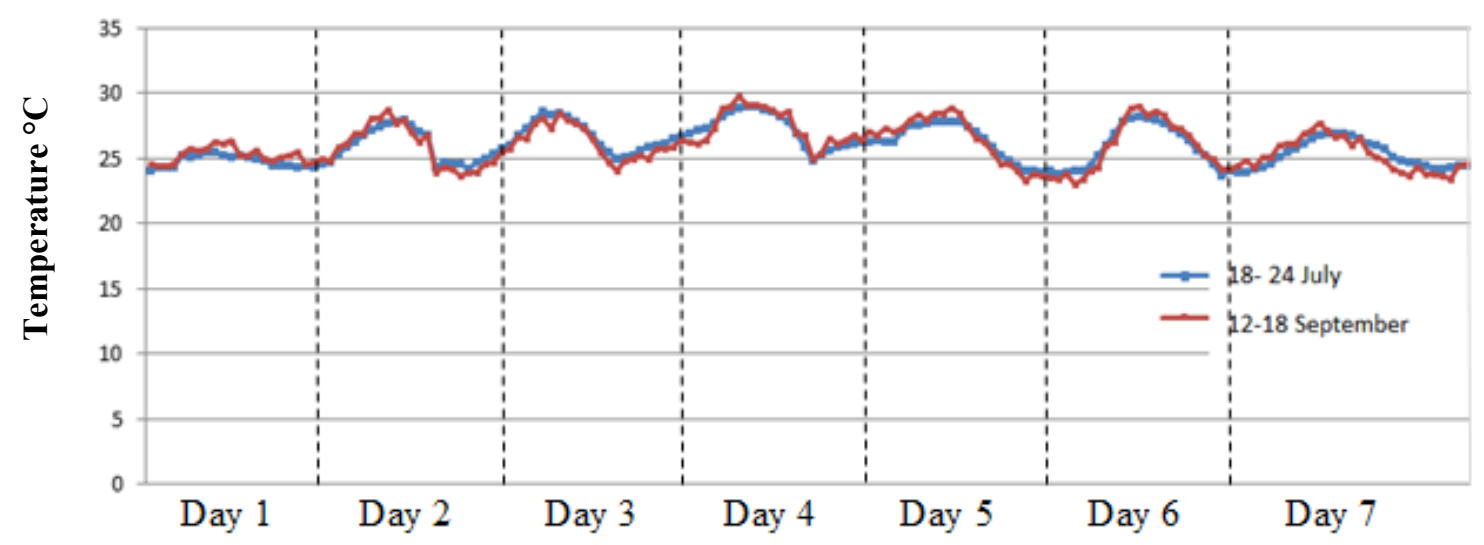


Analysis of hospital gas consumption over two weeks, taken from the natural gas company's web application, has allowed us to calculate Table 4.

Table 4. Energy, cost, and emissions during the week.

\begin{tabular}{ccccc}
\hline Days & $\begin{array}{c}\text { Gas consumption } \\
\left(\mathbf{N m}^{\mathbf{3}}\right)\end{array}$ & $\begin{array}{c}\text { Heating supply } \\
(\mathbf{k W h})\end{array}$ & $\begin{array}{c}\text { Gas cost } \\
(\boldsymbol{\epsilon})\end{array}$ & $\begin{array}{c}\mathbf{C O}_{2} \text { emissions } \\
(\text { ton })\end{array}$ \\
\hline 18-24 July 2011 & $24,188.0$ & 289,772 & $9,283.00$ & 55.2 \\
12-18 September 2011 & $15,239.0$ & 182,557 & $5,849.00$ & 34.8 \\
Reduction (37\%) & $8,949.0$ & 107,215 & $3,434.00$ & 20.4 \\
\hline
\end{tabular}

The financial valuation shown in this table was obtained considering a price of $0.032597 € / \mathrm{kWh}$. This corresponds to the unit price of the variable term of the hospital's gas bill. Using the price considered and the consumption recorded, an estimated saving of 3,434.00 $€$ was made between the two weeks studied.

If this result for one week were extended to the whole of the summer period (June-September $\rightarrow$ 16 weeks), the estimated saving in costs would be:

$$
3,434.00 € / \text { week } \times 16 \text { weeks }=54,944.00 €
$$

Even though, in a large facility such as a 600-bed hospital, gas consumption costs are enormous, being able to cut this amount by around 55,000.00€ represents a considerable saving, and one not to be ignored.

Figure 15 shows the cost of gas each hour over the two weeks analyzed in the study $(1$ week $=168 \mathrm{~h})$. A comparison is made between the cost of one week in July (18-24) 2011, and one week in September (12-18) 2011.

The impact of the four actions implemented in the control system of boilers 5 and 6 related to $\mathrm{CO}_{2}$ emissions over the two-week monitoring period indicated above was calculated, and is shown in Figure 16.

Figure 15. Cost of gas consumption (each hour).

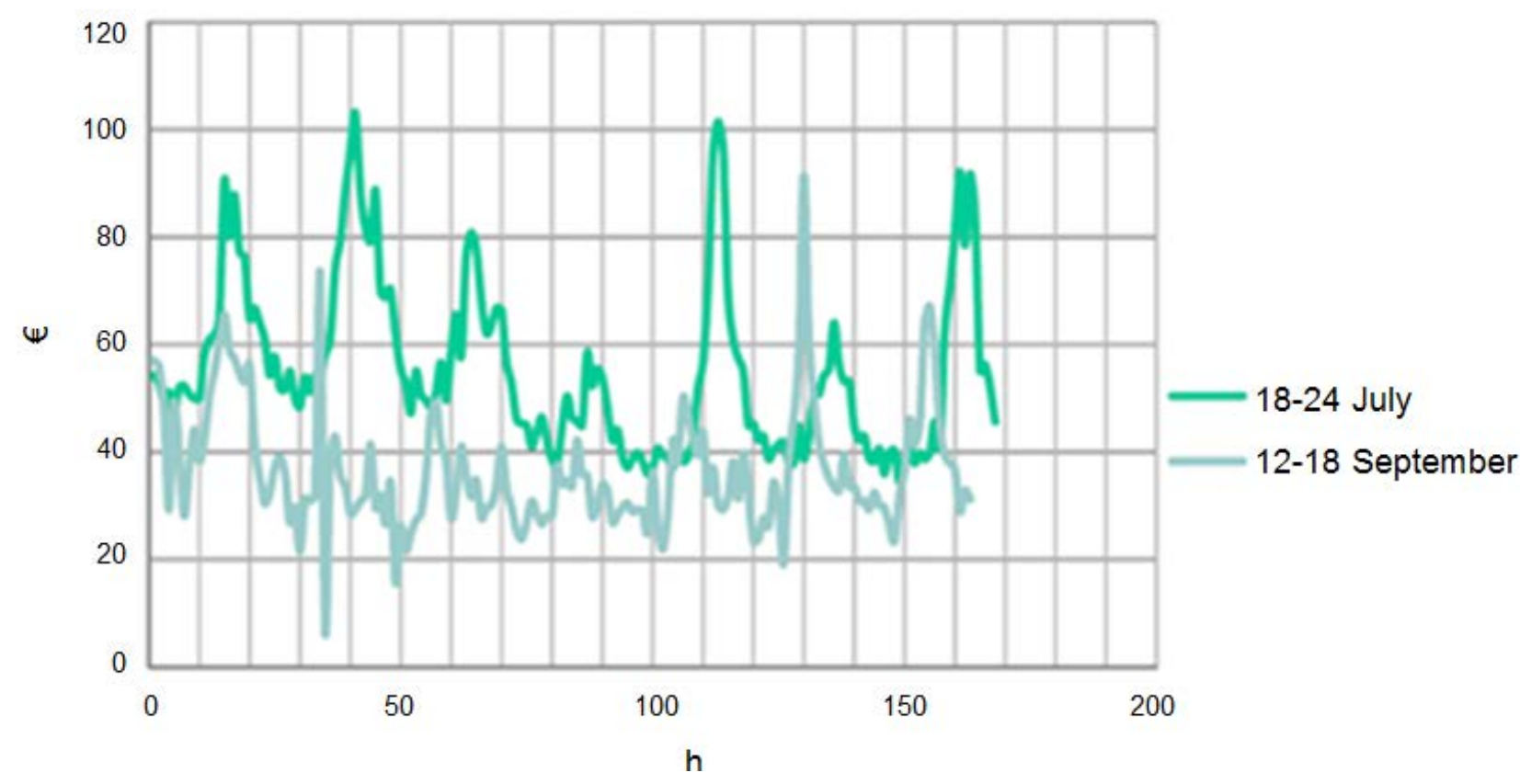


Figure 16. $\mathrm{CO}_{2}$ emissions $(\mathrm{g})$.

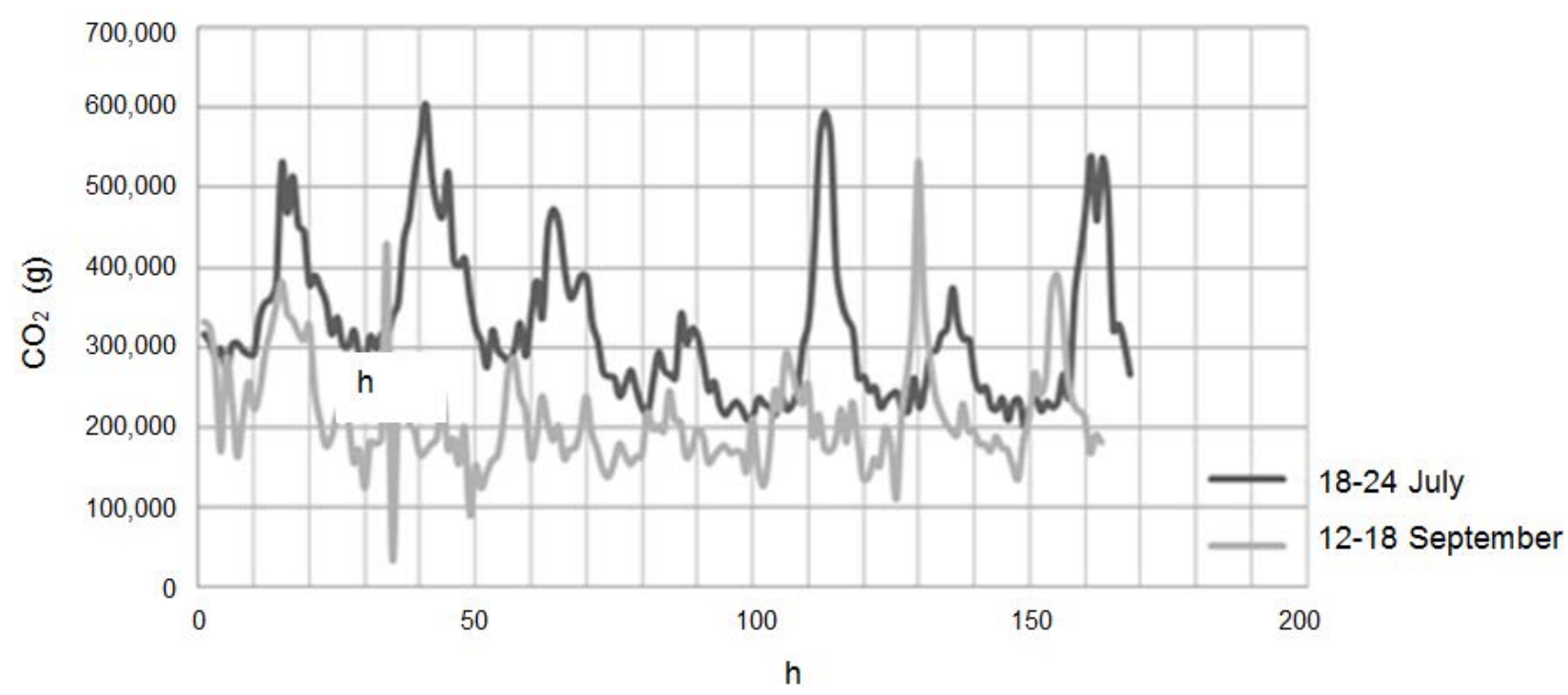

The $\mathrm{CO}_{2}$ values indicated in this figure are calculated from the combustion reaction of natural gas. Analysis of this reaction allows us to estimate the number of grams of $\mathrm{CO}_{2}$ emitted for each $\mathrm{Nm}^{3}$ of natural gas burned:

$$
\frac{1 \mathrm{~mol} \mathrm{CO}_{2}}{1 \mathrm{~mol} \mathrm{CH}_{4}} \times \frac{44 \mathrm{~g} \mathrm{CO}_{2}}{1 \mathrm{~mol} \mathrm{CO}_{2}} \times \frac{1 \mathrm{~mol} \mathrm{CH}_{4}}{16 \mathrm{~g} \mathrm{CH}_{4}} \times \frac{830 \mathrm{~g} \mathrm{CH}_{4}}{1 \mathrm{~m}^{3} \mathrm{~N} \mathrm{CH}_{4}}=2282.2 \frac{\mathrm{g} \mathrm{CO}_{2}}{\mathrm{~m}^{3} \mathrm{~N} \mathrm{CH}_{4}}
$$

$\mathrm{CO}_{2}$ emissions are a direct function of natural gas consumption at the facility. As a result, when the amount of gas used falls, the number of grams of $\mathrm{CO}_{2}$ emitted into the atmosphere also falls.

Figure 15 indicates that emissions corresponding to the week after control actions were taken (12-18 September 2011) are clearly lower. $\mathrm{CO}_{2}$ emissions due to the improved control system of boilers 5 and 6 are $37 \%$ in the comparative study performed for the two weeks chosen. This represents a 20-ton reduction in the $\mathrm{CO}_{2}$ emitted to the atmosphere.

\section{Conclusions}

The actions performed to regulate and control the hospital boilers allow us to conclude that:

- The reduction in the minimum limit of the burner power has managed to prevent the boilerfrom continually switching on and off, as a result of reaching high working temperatures at moments of low demand.

- Appropriate PID controller tuning to regulate the boiler burner allows hot water supply temperature variations to be smoothed. Temperature peaks are smoothed and are shorter. When dealing with changes in hospital heat demand, the boilers are able to respond rapidly to changes and quickly stabilize.

- Implementing a boiler control sequence leads to a decrease in the time intervals in which the boiler is operated at high power being achieved. This increases boiler lifespan as well as more efficient running. Thanks to the support boiler, disturbances caused by changes in hospital heat demand are damped more quickly, thus reducing peak temperatures in the hot water. 
- After implementing the variable setpoint, the hot water supply temperature of the boiler increases and decreases with the outdoor air temperature throughout the day, thereby reducing temperature fluctuations in the primary circuit, so it operates more in line with hospital heat demand.

We conclude that the four well-designed actions implemented to improve the control strategy of the hospital boilers are able to provide heating in a highly efficient manner. Control cannot overcome a facility's design faults, but can improve its performance, as has been evidenced by the results achieved in this paper.

Financial analysis points to a 55,000 € reduction in costs in summer (June-September), as compared to the costs with the manufacturer's original control system. Furthermore, the system was able to cut $\mathrm{CO}_{2}$ emissions by over 20 tons between June and September. There is a total primary energy saving that corresponds to a $37 \%$ reduction in $\mathrm{CO}_{2}$ emissionsas compared to the reference installation.

These findings show that a boiler control system which implements the actions described will prove an environmentally friendly and financially feasible option for hospital heating.

\section{Author Contributions}

Juan-Carlos Fraile and Julio San-José designed the control actions, proposed and analyzed the test results, and wrote and revised the manuscript. Ana Gonzalez-Alonso developed control software and human-machine interface for PLC and PC. All authors read and approved the final manuscript.

\section{Conflicts of Interest}

The authors declare no conflict of interest.

\section{References}

1. Bizzarri, G.; Morini, G.L. New technologies for an effective energy retrofit of hospitals. Appl. Therm. Eng. 2006, 26, 161-169.

2. Barwig, F.; House, J.M.; Klaassen, C.J.; Ardehali, M.M.; Smith, T.F. The national building controls information program. In Proceedings of the ACEEE Summer Study on Energy-Efficiency in Buildings, Washington, DC, USA, 18-23 August 2002; pp. 1-14.

3. Commercial Buildings Energy Consumption Survey: Consumption \& Efficiency. Available online: http://www.eia.gov/consumption/commercial/ (accessed on 30 August 2013).

4. Duarte, C.; Acker, B.; Grosshans, R.; Manic, M.; van den Wymelenberg, K.; Rieger, C. Prioritizing and visualizing energy management and control system data to provide actionable information for building operators. In Proceedings of the Western Energy Policy Research Conference, Boise, ID, USA, 25-26 August 2011.

5. Wijayasekara, D.; Manic, M.; Rieger, C. Computational intelligence based anomaly detection for Building Energy Management Systems. In Proceeding of the 5th International Symposium on Resilient Control Systems, Salt Lake City, UT, USA, 14-16 August 2012; pp. 77-82.

6. San-José, J.F.; Guijarro, A.; Castro, F.; Villafreula, J.M. Indicadores de energía térmica en los hospitales de Castilla y León. Todo Hosp. 2009, 260, 641-648. (In Spanish) 
7. Hirst, E.; Clinton, J.; Geller, H.; Kroner, W. Energy Efficiency in Buildings: Progress and Promise; American Council for an Energy Efficient Economy: Washington, DC, USA, 2008.

8. Granzer, W.; Kastner, W. Communication services for secure building automation networks. In Proceedings of the IEEE International Symposium on Industrial Electronics Bari, Bari, Italy, 4-7 July 2010; pp. 3380-3385.

9. Vakiloroaya, V. Energy-efficient HVAC systems-empirical modelling and gradient optimization. Autom. Constr. 2013, 31, 176-185.

10. Chung, M.; Park, H.C. Development of a software package for community energy system assessment—Part I: Building a load estimator. Energy 2010, 35, 2767-2776.

11. Bujak, J. Mathematical modelling of a steam boiler room research termal efficiency. Energy 2008, 33, 1779-1787.

12. Klein, L.; Kwak, J.Y.; Kavulya, G.; Jazizadeh, F.; Becerik-Gerber, B.; Varakantham, P.; Tambe, M. Coordinating occupant behavior for building energy and comfort management using multi-agent systems. Autom. Constr. 2012, 22, 525-536.

13. Yoshida, S.; Ito, K.; Yokoyama, R. Sensitivity analysis in structure optimization of energy supply systems for a hospital. Energy Convers. Manag. 2007, 48, 2836-2843.

14. Ma, Z.; Wang, S. Supervisory and optimal control of central chiller plants using simplified adaptive models and genetic algorithm. Appl. Energy 2011, 88, 198-211.

15. Beghi, A.; Cecchinato, I. Modelling and adaptive control of smell capacity chillers for HVAC applications. Appl. Therm. Eng. 2011, 31, 1125-1134.

16. Liao, C.; Barooah, P. An integrated approach to occupancy modeling and estimation in commercial buildings. In Proceedings of the American Control Conference, Baltimore, MD, USA, 30 June-2 July 2010; pp. 3130-3135.

17. West, S.R.; Ward, J.K.; Wall, J. Trial results from a model predictive control and optimisation system for commercial building HVAC. Energy Build. 2014, 72, 271-279.

18. Ahmadzadehtalatapeh, M.; Yau, Y.H. The application of heat pipe heat exchangers to improve the air quality and reduce the energy consumption of the air conditioning system in a hospital ward-A full year model simulation. Energy Build. 2011, 43, 2344-2355.

19. Congradac, V.; Prebircevis, B.; Petrovacki, N. Methods for assessing energy saving in hospitals using various control techniques. Energy Build. 2014, 69, 85-92.

20. Diakakia, C.; Grigoroudisb, E.; Kolokotsaa, D. Towards a multi-objective optimization approach for improving energy efficiency in buildings. Energy Build. 2008, 40, 1747-1754.

21. Boilers for Central Heating; Boilers for Wood, Straw and Similar Fuels; Terms Requirements, Testing; DIN 4702-4; Deutsches Institut für Normung e.V. (German National Standard): Berlin, Germany, 1990.

22. Vulcano Sadeca Company. Available online: http://www.vulcanosadeca.es/en/principal.html (accessed on 7 May 2014).

23. Dounis, A.I.; Caraiscos, C. Advancedcontrolsystems engineering for energy and comfort management in a building environment-A review. Renew. Sustain. Energy Rev. 2009, 13, 1246-1261. 
24. Kolokotsa, D.; Stavrakakis, G.S.; Kalaitzakis, K.; Agoris, D. Genetic algorithms optimized fuzzy controller for the indoor environmental management in buildings implemented using PLC and local operating networks. Artif. Intell. 2002, 15, 417-428.

25. TREND Company. Data Sheet 963 Supervisor. Available online: https://partners.trendcontrols. com/trendproducts/cd/it/pdf/en-ta200636-uk0yr0508.pdf (accessed on 27 May 2013).

26. TREND Company. 963 User Guide. Available online: https://partners.trendcontrols.com/ trendproducts/cd/ru/pdf/en-tc200635-uk0yr0308.pdf (accessed on 27 May 2013).

27. Kazemian, H.B. Comparative Study of a Learning Fuzzy PID Controller and a Self-Tuning Controller. ISA Trans. 2001, 40, 245-253.

(C) 2014 by the authors; licensee MDPI, Basel, Switzerland. This article is an open access article distributed under the terms and conditions of the Creative Commons Attribution license (http://creativecommons.org/licenses/by/3.0/). 